\title{
Pengukuran Tekanan Darah Non-Invasive Tanpa Manset Menggunakan Metode Pulse Transit Time Berbasis Machine Learning Multivariat Regresi
}

\author{
Ernia Susana \\ Jurusan Teknik Elektromedik, Politeknik Kesehatan Kemenkes Jakarta II, Indonesia \\ Email: erniasusana@gmail.com
}

\begin{abstract}
Non-Invasive Blood Pressure Measurement Without Cuff Using the Pulse Transit Time Method Based on Multivariate Regression Machine Learning. Currently used noninvasive blood pressure (NIBP) measurements (oscillometric method) has disadvantages related to pumping cuffs which can cause discomfort for patients due to pressure from pumping cuffs. The aim of this study was to measure blood pressure in a non-invasive manner without cuffs with the Pulse Transit Time (PTT) methodbase on machine learning technology.The blood pressure measurement by the PTT method is obtained from the calculation of the distance of the R-ECG wave with the peak signal photoplethysmogram (PPG). The main problem of the PTT method in some previous studies is that the estimation of systolic (SBP) and diastolic (DBP) values is still inaccurate. The blood pressure measurement method in this study used a combination of PTT calculations with machine learning multivariate regression. Therefore expected to obtain a more accurate estimate of systolic (SBP) and diastolic blood pressure (DBP). This study is a laboratory experiment research on 30 healthy volunteers aged $20 \pm 1$ years. The measurement of the blood pressure value of the PTT-to-oscillometric method is $5 \pm 5 \mathrm{mmHg}$. The blood pressure values generated by this PTT method have a p-value for the sequential estimation of SBP and DBP of 0.7374 and 0.0262 .
\end{abstract}

Keywords: Machine learning, NIBP, Oscillometric, PTT, PPG

\begin{abstract}
Abstrak: Pengukuran Tekanan Darah Non-Invasive Tanpa Manset Menggunakan Metode Pulse Transit Time Berbasis Machine Learning Multivariat Regresi. Pengukuran tekanan darah non-invasif (NIBP) yang digunakan saat ini (metode osilometrik) memiliki kelemahan terkait dengan pemompaan manset yang dapat menyebabkan ketidaknyamanan bagi pasien karena tekanan yang diakibatkannya. Tujuan penelitian ini adalah untuk mengukur tekanan darah secara non-invasive tanpa manset dengan menggunakan metode pulse transit time (PTT) berbasis machine learning. Pengukuran tekanan darah melalui metode PTT didapat dari hasil perhitungan jarak gelombang R-EKG dengan sinyal puncak PPG (photoplethysmogram). Masalah utama metode PTT pada beberapa penelitian sebelumnya adalah masih rendahnya tingkat akurasi estimasi dari nilai sistolik (SBP) dan diastolik (DBP). Metode pengukuran tekanan darah pada penelitian ini menggunakan perhitungan PTT berbasis machine learning multivariate regresi. Diharapkan hasilnya akan mendapatkan estimasi nilai tekanan darah sistolik (SBP) dan diastolik (DBP) yang lebih akurat. Penelitian ini merupakan penelitian eksperimen laboratorium terhadap 30 sukarelawan sehat berumur $20 \pm 1$ tahun. Pengukuran nilai tekanan darah metode PTT terhadap osilometrikadalah sebesar $5 \pm 5 \mathrm{mmHg}$. Nilai tekanan darah yang dihasilkan melalui metode PTT ini memiliki nilai $p$-value untuk estimasi SBP dan DBP secara berurutan adalah sebesar 0,7374 dan 0,0262 .
\end{abstract}

Kata kunci: Machine learning, NIBP, Osilometrik, PTT, PPG

\section{PENDAHULUAN}

Penyakit jantung koroner, pembuluh darah dan stroke saat ini merupakan penyebab utama kematian dan kecacatan yang dialami oleh orang dewasa di negara maju (Sierra \& Sierra, 2008). Tidak menutup kemungkinan hal tersebut kini terjadi juga di Indonesia (Kementerian Kesehatan
Republik Indonesia, 2017). Salah satu parameter penting dalam mendeteksi dini penyakit tersebut adalah parameter blood pressure yang lebih dikenal dengan istilah tekanan darah.

Tekanan darah didefinisikan sebagai kekuatan yang diperlukan agar darah dapat mengalir di dalam pembuluh darah dan beredar mencapai ke seluruh jaringan tubuh manusia 
(Huynh \& Jafari, 2018). Besarnya tekanan darah sangat bergantung pada elastisitas, kelenturan dan tebal dinding dari pembuluh darah arteri (Tjahjadi \& Ramli, 2017).

Parameter tekanan darah, diukur berdasarkan dua kondisi berbeda yaitu tekanan darah sistolik (SBP) dan tekanan darah diastolik (DBP). Tekanan sistolik (SBP) adalah tekanan yang dihasilkan otot jantung saat mendorong darah dari ventrikel kiri ke aorta yaitu tekanan pada saat otot ventrikel jantung memompa sedang tekanan diastolik (DBP) adalah tekanan pada dinding arteri dan pembuluh darah akibat mengendurnya otot ventrikel jantung yaitu tekanan pada saat otot atrium jantung kontraksi dan darah menuju ventrikel atau dengan kata lain pembuluh darah jantung selesai memompa (Gunawan, 2001).

Tekanan darah merupakan rasio nilai SBP terhadap DBP (SBP/DBP) dengan satuan tekanan darah adalah mmHg. Nilai tekanan darah normal berdasarkan Joint National Committee on Prevention, Detection, Evaluation and Treatment of High Blood Pressure klasifikasi kategori JNC 6 dan JNC 7 secara berurutan adalah 120/80 $129 / 84 \mathrm{mmHg}$ dan $<120 / 80 \mathrm{mmHg}$ (Brien et al, 2010).

Pengukuran tekanan darah dapat dilakukan dengan teknik invasive maupun non-invasive. Metode yang digunakan pada teknik invasive adalah metode kateterisasi (artery cannulation) yaitu dengan memasukkan kanula arteri lewat pembuluh intravena pasien. Teknik invasive memungkinkan pengukuran tekanan darah dilakukan secara terus menerus dan akurat. Tetapi hal ini tentu sangat tidak nyaman karena melukai pasien dan bekas luka berpotensi menyebabkan infeksi bagi pasien.

Teknik non-invasive adalah teknik pengukuran tekanan darah dengan menggunakan cuff (manset). Teknik non-invasive terdiri dari metode osilometrik dan dan auskultasi (Daochai \& Sroykham, 2011).

Saat ini, pengukuran dengan teknik noninvasive digunakan secara luas karena tidak melukai pasien tetapi tetap menimbulkan ketidaknyamanan berupa timbulnya rasa sakit akibat meningkatnya tekanan dari aktifitas pemompaan manset .

Kedua teknik pengukuran non-invasive diatas membutuhkan pengawasan dan persiapan khusus serta menimbulkan ketidaknyamanan bagi pasien selama pemeriksaan berlangsung. Pengembangan metode pengukuran non-invasive tekanan darah terus dikembangkan hingga kini. Salah satunya adalah metode PTT (Tjahjadi \& Ramli, 2017).
Metode PTT memanfaatkan delay waktu antara munculnya gelombang R-puncak EKG dengan sinyal puncak photoplethysmogram (PPG) sehingga mendapatkan nilai estimasi dari tekanan darah sistolik (SBP) dan diastolik (DBP). Variabel parameter PTT didapat dari ekstraksi antara sinyal EKG dan PPG yang dihasilkan dari respon sistem jantung dan pembuluh darah (kardiovaskular) (Gesche et al, 2012).

Era industri 4.0 memberikan peluang bagi pekerjaan data science dan machine learning (Sugiarta, 2018). Terrmasuk didalamnya pemanfaatan machine learning dalam dunia kedokteran. Telah banyak penelitian yang menunjukkan bahwa kemampuan machine learning dapat digunakan dalam dunia kedokteran (Holzinger, n.d.). Contoh penerapan machine learning dalam bidang kedokteran adalah kemampuan mendeteksi penyakit seseorang dari gejala yang ada.

Machine learning merupakan salah satu cabang dari disiplin ilmu artificial intelligence. Machine learning bekerja berdasarkan data dari analisa data science yang dipelajarinya. Data yang dipelajari baik terstruktur maupun tidak terstruktur dapat dianalisa dan kemudian dimodelkan dengan pendekatan algoritma tertentu sesuai dengan kebutuhan dalam pemanfaatan machine learning.

Hasil akhir dari machine learning adalah prediksi dan rekomendasi (Sugiarta, 2018). Semakin banyak data yang diterima dan dianalisis melalui algoritmanya, maka akan semakin baik kemampuan artificial intelligence dalam membuat prediksi.

Dalam penelitian ini, machine learning digunakan untuk mendapatkan algoritma dari data ukur metode PTT yang memanfaatkan delay waktu antara munculnya gelombang R-puncak $E K G$ dengan sinyal puncak PPG serta intervensi heart rate dalam mendapatkan nilai estimasi dari tekanan darah SBP dan DBP.

Model analisis multivariat regresi dipilih karena pengolahan variabel penelitian ini melibatkan jumlah variabel independen sebanyak $\mathrm{n}$ dan lebih dari satu. Tujuannya adalah mencari pengaruh variabel-variabel tersebut terhadap suatu output (variabel dependen) secara simultan atau serentak.

Variabel dependen (output) berupa nilai estimasi SBP atau DBP sedang variabel independen terdiri dari nilai PTT yang didapat dari delay waktu munculnya gelombang Rpuncak EKG dengan puncak sinyal PPG beserta heart rate.

Eksplorasi metode PTT pada beberapa penelitian dilakukan dalam berbagai teknik 
termasuk mengkombinasi data pendukung lain yang ditujukan untuk mendapatkan nilai estimasi SBP dan DBP yang paling akurat (Gesche et al, 2012).

\section{METODE}

Penelitian ini merupakan penelitian eksperimen laboratorium kuantitatif terhadap 30 sukarelawan sehat berumur $20 \pm 1$ tahun.

Penempatan elektrode pada patient monitor untuk mendapatkan data dari masingmasing metode baik osilometrik maupun PTT ditunjukkan gambar 1 . Teknik penentuan nilai PTT untuk estimasi SBP dan DBP dalam penelitian ini didasarkan pada jarak delay waktu antara munculnya gelombang R-puncak EKG dengan sinyal puncak PPG (Gesche, 2012).

Pengambilan data tekanan darah dilakukan dengan komparasi 2 metode yaitu osilometrik dan pulse transit time (PTT) terhadap semua sukarelawan dalam posisi rest (berbaring) menggunakan patient monitor 3 lead dan penempatan finger sensor pada jari manis.

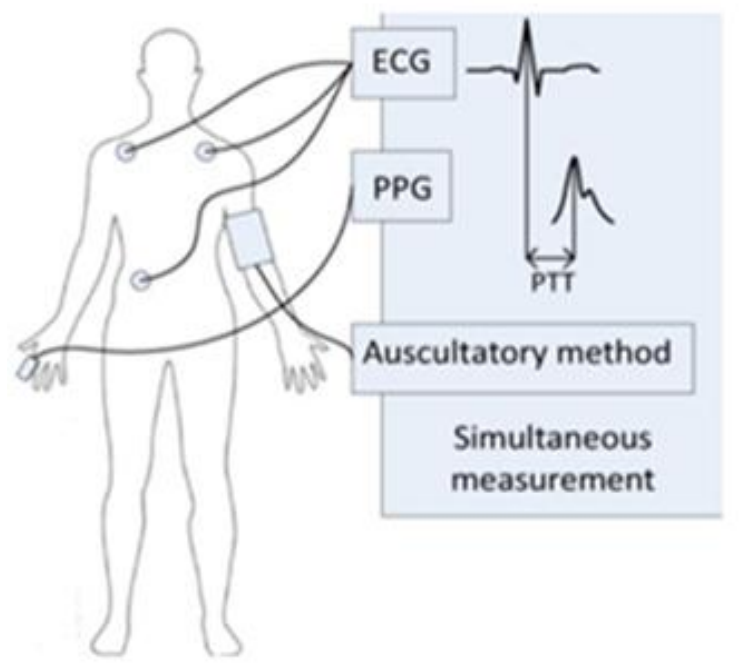

\section{Gambar 1. Penempatan elektrode}

(Peter, Noury, \& Cerny, 2014)

Pada tahap awal, sukarelawan akan diukur dengan metode osilometrik menggunakan sebanyak 3 kali pengambilan data dengan jeda waktu antara pengukuran 1 terhadap pengukuran selanjutnya adalah 10 menit. Selanjutnya dilakukan pengukuran NIBP dengan metode PTT untuk mendapatkan hasil sinyal $P P G$ dan EKG serta heart rate sebanyak 3 kali pengukuran dengan jeda waktu antara pengukuran 1 terhadap pengukuran selanjutnya adalah 5 menit. Prediksi waktu pengambilan data keseluruhan per sukarelawan adalah 20 menit. Semua alat yang digunakan dalam penelitian telah terkalibrasi. Pelaksanaan pengambilan data ditunjukkan pada gambar 2.

Nilai algoritma ertimasi SBP dan DBP dihasilkan dari model $R$-machine learning yang ditunjukkan gambar 3 .
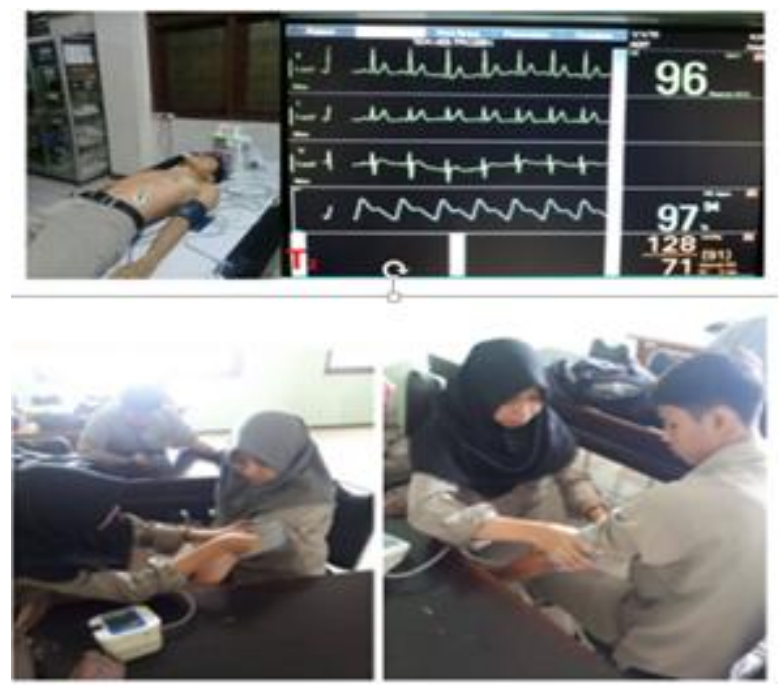

Gambar 2. Pelaksanaan pengambilan data responden

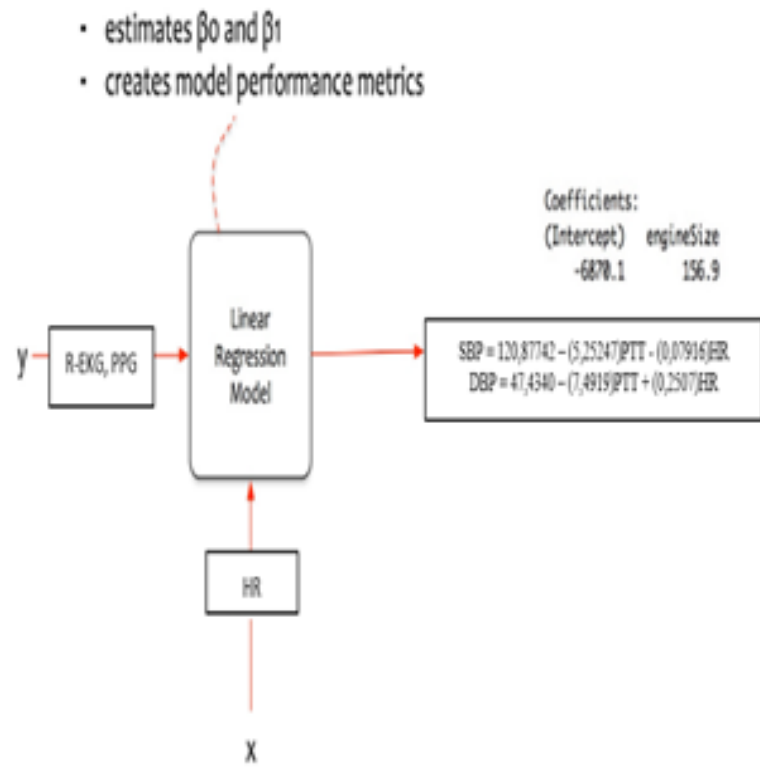

Gambar 3. Model multivariat regresi untuk sistolik (Pradeep Menon, 2017)

Nilai PTT untuk SBP dan DBP dari sinyal PPG dan EKG yang diperoleh dari patient monitor, selanjutnya diolah dan dieksploitasi lebih lanjut menggunakan software digitimizer untuk mengestimasi delay waktu yang terjadi sebagai data olahan PTT selanjutnya. Satu variabel dependen (PTT) diprediksi dengan menggunakan satu variabel independen (sistolik).

Penelitian ini tidak menggunakan obatobatan dan tindakan invasive. Sebelumnya 
responden menandatangani informed concern sebagai persetujuan terhadap tindakan yang akan dilakukan terhadap dirinya.

\section{HASIL}

Hasil penelitian dijelaskan dalam tabel dan gambar berikut. Metode PTT diujikan pada 30 sukarelawan sehat sebagai responden dengan rentang umur $20 \pm 1$ tahun. Karakteristiknya responden dijelaskan pada tabel 1 dan 2 .

\section{Tabel 1. Karakteristik Responden Penelitian}

\begin{tabular}{lcc}
\hline \multicolumn{1}{c}{$\begin{array}{c}\text { Karakteristik } \\
\text { Sukarelawan }\end{array}$} & f & \% \\
\hline Jenis Kelamin & 21 & $70 \%$ \\
Laki-Laki & 9 & $30 \%$ \\
Perempuan & & \\
\hline
\end{tabular}

Tabel 2. Karakteristik TB/BB Responden

\begin{tabular}{lcccc}
\hline \multicolumn{1}{c}{ TB/BB } & $\mathbf{f}$ & $\boldsymbol{\Sigma}$ & Min & Max \\
Sukarelawan & & & & \\
\hline Laki-Laki & 21 & & & \\
TB $(\mathrm{cm})$ & & 167 & 154 & 182 \\
BB $(\mathrm{Kg})$ & & 65,5 & 46 & 123 \\
Perempuan & 9 & & & \\
TB $(\mathrm{cm})$ & & 156 & 168 & 150 \\
BB $(\mathrm{Kg})$ & & 54 & 47 & 68 \\
\hline
\end{tabular}

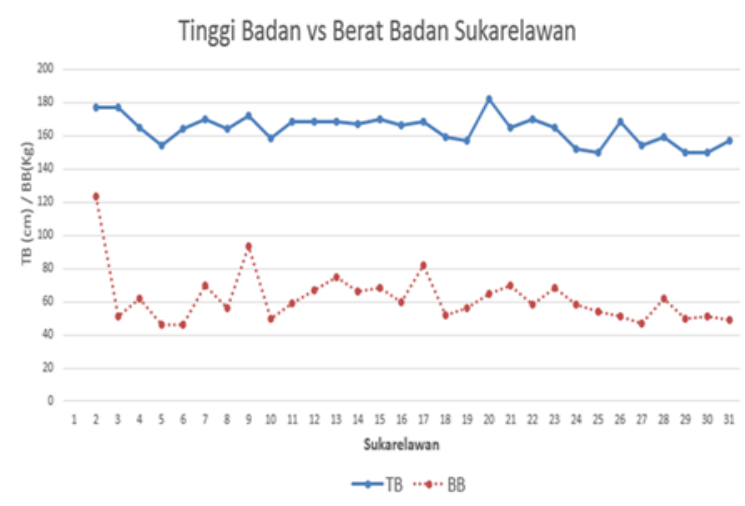

\section{Gambar 4. TB vs BB Responden}

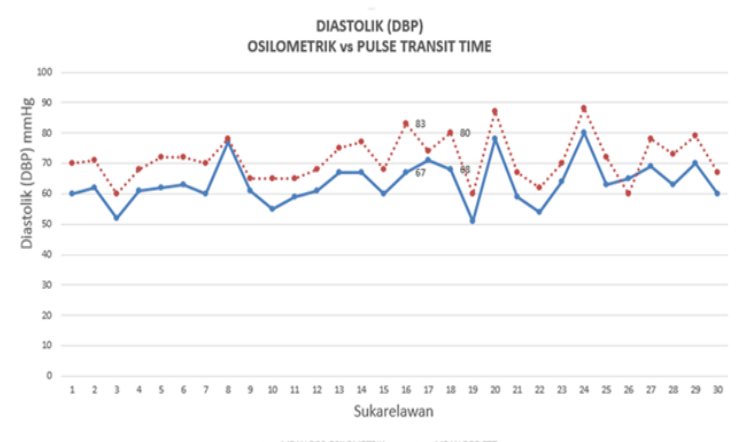

Gambar 5. Pengukuran Diastolik (DBP): Osilometrik vs Pulse Transit Time

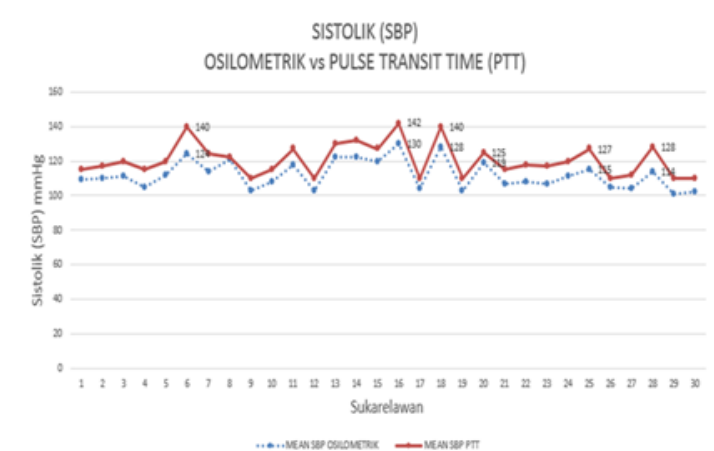

Gambar 6. Pengukuran Sistolik (SBP): Osilometrik vs Pulse Transit Time

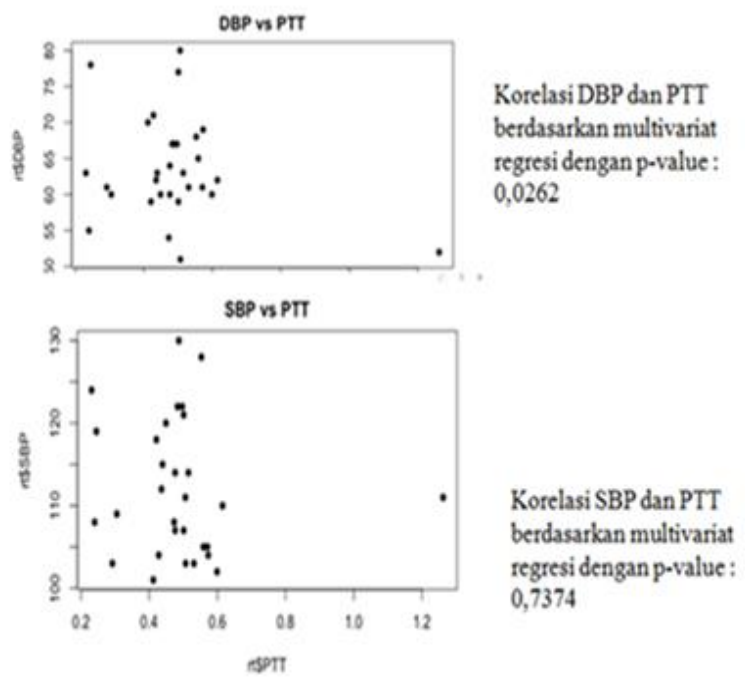

Gambar 7. Korelasi SBP dan DBP terhadap metode Pulse Transit Time (PTT)

Pemanfaatan aplikasi machine learning berbasis multivariat regresi menghasilkan formula perhitungan estimasi SBP dan DBP sebagai berikut :

$\mathrm{SBP}=$

120,87742-(5,25247)PTT - $(0,07916) H R$.......(1)

$\mathrm{DBP}=$

47,4340-(7,4919) PTT + $(0,2507) \mathrm{HR}$

\section{PEMBAHASAN}

Penelitian terkait metode PTT dilakukan pada 30 sukarelawan sehat sebagai responden dengan rentang umur $20 \pm 1$ tahun dengan karakteristik berdasarkan jenis kelamin adalah $70 \%$ (21) laki-laki dan 30\% (9) perempuan sebagaimana ditunjukkan pada tabel 1 .

Tinggi badan dan berat badan rata-rata responden laki-laki dan perempuan sebagaimana tabel 2 secara berurutan adalah adalah responden laki-laki TB 167 dengan BB 65,5 sedangkan responden wanita TB 156 dengan BB 54. 
Grafik tinggi badan masing-masing responden ditunjukkan pada gambar 4.

Gambar grafik 5 dan 6 menunjukkan komparasi hasil pengukuran antara metode osilometrik dan PTT dari masing-masing responden yang menghasilkan bias pengukuran yang berkisar antara $5 \pm 5 \mathrm{mmHg}$. Metode osilometrik dalam hal ini menjadi gold standar pengukuran sebagai metode pengukuran yang umum dilakukan.

Dari grafik tersebut, ditemukan responden yang memiliki nilai bias pengukuran diatas $5 \pm 5$ $\mathrm{mmHg}$. Untuk DBP terdapat 2 responden yaitu 16 dan 18 sedang untuk SBP terdapat 6 responden yang diantaranya adalah responden nomor 6, 16, 18, 20, 25 dan 28. Bias pengukuran dari 6 responden tersebut tidak melebihi $3 \mathrm{mmHg}$ dari jangkauan bias $5 \pm 5 \mathrm{mmHg}$. Secara keseluruhan hasil pengukuran 6 responden tersebut tidak akan menurunkan kualitas pengukuran sehingga diputuskan untuk tidak mengeliminasinya.

Berdasarkan gambar 7, hasil pengukuran dengan metode PTT menunjukkan korelasi yang cukup kuat antara tekanan darah dengan parameter elektrokardiogram, photoplethysmograph $\left(\mathrm{SPO}_{2}\right)$ dan heart rate (HR) dari peralatan patient monitor. Korelasi antara SBP dan DBP menunjukan bahwa perhitungan estimasi DBP lebih signifikan dibandingkan dengan estimasi perhitungan SBP.

Nilai $p$-value yang dihasilkan dari formula perhitungan DBP adalah sebesar 0,0262 sedangkan nilai $p$-value formula SBP adalah sebesar 0,7374. Semakin kecil nilai $p$-value maka semakin baik variabel tersebut. Semakin tinggi semakin buruk. Dari hasil nilai p-value yang dihasilkan dalam penelitian ini, nilai $p$-value DBP berada dibawah 0,05 sehingga secara signifikan nilai PTT dan heart rate berpengaruh terhadap tekanan darah diastolik. Nilai $p$-value dari SBP berada jauh diatas 0,05 sehingga nilai PTT semakin tidak signifikan (semakin kecil pengaruhnya) terhadap variabel sistolik.

Berdasarkan algoritma yang dihasilkan machine learning untuk perhitungan SBP dan DBP yang ditunjukkan oleh persamaan 1 dan 2 dapat disimpulkan bahwa semakin kecil delay waktu yang terjadi (PTT) maka semakin tinggi estimasi perhitungan SBP dan DBP yang dihasilkan sedangkan nilai heart rate tidak berdampak signifikan terhadap estimasi SBP dan DBP yang terjadi.

Nilai estimasi tekanan darah sebagai variabel dependen sangat ditentukan oleh lamanya delay waktu yang terjadi antara munculnya gelombang R-puncak EKG dengan sinyal puncak PPG yang dijadikan sebagai dasar perhitungan PTT dan kondisi heart rate. Waktu perekaman yang singkat, pemasangan elektrode dan finger sensor pada saat pengambilan data dan ketelitian perhitungan waktu delay yang dihasilkan PTT secara keseluruhan akan mempengaruhi bias perhitungan dalam penentuan nilai PTT oleh software digimizer.

Eksplorasi metode PTT dalam berbagai teknik terus berlangsung untuk tujuan mendapatkan nilai estimasi SBP dan DBP yang paling akurat. Studi literatur terhadap penelitian sebelumnya (Selvaraj, 2016) pada 50 pria muda yang sehat (usia rata-rata 22 tahun) terkait pengukuran NIBP pada lokasi jari dan pergelangan tangan dengan model algoritma machine learning yang berbeda yaitu linier regresi menunjukkan korelasi linier 0,41 untuk PTT vs DBP dan 0,39 untuk PTT vs SBP.

Komparasi dari penelitian di atas menunjukkan bahwa mekanisme pengukuran tekanan darah yang berbeda akan mempengaruhi besarnya PTT. Selain itu pengembangan metode PTT yang melibatkan data dukung lain, dalam penelitian ini melibatkan heart rate, menunjukkan nilai signifikan yang lebih baik utamanya pada pengukuran DBP dibanding dengan pengukuran yang hanya menggunakan 1 variabel independen. Pengukuran SBP masih perlu diperbaiki khususnya dalam menentukan eksplorasi penentuan titik paling tepat baik pada sinyal EKG maupun PPG sehingga menghasilkan nilai PTT yang signifikan terhadap SBP.

\section{SIMPULAN}

Secara keseluruhan, nilai estimasi DBP lebih konsisten dibanding SBP pada pengujian 30 sukarelawan sehat berumur $20 \pm 1$ tahun. Nilai $p$ value untuk estimasi SBP dan DBP yang dihasilkan dari penelitian ini secara berurutan adalah sebesar 0,7374 dan 0,0262. Artinya secara signifikan nilai PTT dan heart rate berpengaruh terhadap tekanan darah DBP dibanding SBP. Bias pengukuran antara SBP dan DBP metode PTT terhadap osilometrik adalah $5 \pm 5 \mathrm{mmHg}$. Algoritma multivariat regresi menunjukkan bahwa semakin kecil delay waktu yang terjadi antara munculnya gelombang R-puncak EKG dengan sinyal puncak PPG maka semakin tinggi estimasi perhitungan SBP dan DBP yang dihasilkan sedang nilai heart rate tidak berdampak signifikan terhadap estimasi SBP dan DBP yang terjadi. Perkembangan artificial intelligent yang begitu pesat di era 4.0, memungkinkan metode PTT dapat diterapkan 
pada patient monitor. Dengan metode PTT, nilai sistolik (SBP) dan diastolik (DBP) dapat dihasilkan dari parameter $\mathrm{EKG}$ dan $\mathrm{SPO}_{2}$

\section{DAFTAR PUSTAKA}

Brien, E. O., Atkins, N., Stergiou, G., \& Karpettas, N. (2010). European Society of Hypertension International Protocol revision 2010 for the validation of blood pressure measuring devices in adults. International Protocol for Device Validation, 15(1), 2338.

https://doi.org/10.1097/MBP.0b013e32833 $60 \mathrm{e} 98$

Daochai, \& Sroykham. (2011). Non-invasive blood pressure measurement: Auscultatory method versus oscillometric method Noninvasive Blood Pressure Measurement: Auscultatory method versus Oscillometric method. Biomedical Engineering International Conferense, (January). https://doi.org/10.1109/BMEiCon.2012.61 72056

Gesche, et al. (2012). Continuous blood pressure measurement by using the pulse transit time: comparison to a cuff-based method. European Journal of Applied Physiology, 112(1), 309-315. https://doi.org/10.1007/s00421-011-1983-3

Gunawan, L. (2001). Hipertensi Tekanan Darah Tinggi (8th ed.). Yogyakarta: Kanisius.

Holzinger, A. (n.d.). Machine Learning for Health Informatics. https://doi.org/10.1007/978-3319-50478-0

Huynh, T. H., \& Jafari. (2018). Noninvasive Cuffless Blood Pressure Estimation Using Pulse Transit Time and Impedance. IEEE Transactions on Biomedical Engineering, $P P(\mathrm{c}), 1$. https://doi.org/10.1109/TBME.2018.2865751

Kementerian Kesehatan Republik Indonesia. (2017). Penyakit Jantung Penyebab Kematian Tertinggi, Kemenkes Ingatkan CERDIK. Jakarta. sehingga tidak perlu lagi menggunakan cuff (manset), hasil pengamatan dapat dilaksanakan secara kontinu dan real time. http://www.depkes.go.id/article/view/170731 00005/penyakit-jantung-penyebab-kematiantertinggi-kemenkes-ingatkan-cerdik-.html

Peter, L., Noury, N., \& Cerny, M. (2014). A review of methods for non-invasive and continuous blood pressure monitoring: Pulse transit time method is promising? IRBM, 35(5), 271282.

https://doi.org/10.1016/J.IRBM.2014.07.002

Pradeep Menon. (2017). Data Science Simplified Part 5: Multivariate Regression Models.

Selvaraj, N. (2016). Assessment of pulse transit/arrival time as noninvasive blood pressure predictors in finger and earlobe sites. 2016 IEEE Healthcare Innovation Point-of-Care Technologies Conference, HI-POCT 2016, 200-203. https://doi.org/10.1109/HIC.2016.7797731

Sierra, C., \& Sierra, A. de la. (2008). Early detection and management of the high-risk patient with elevated blood pressure. Vascular Health and Risk Management, 4(2), 289-296. Barcelona: Dove Medical Press Limited.

Sugiarta, A. I. (2018). Data Science dan Machine Learning sebagai Peluang di Era Revolusi Industri 4.

https://www.detiksumsel.com/datascience-dan-machine-learning-sebagaipeluang-di-era-revolusi-industri-4-0/

Tjahjadi, H., \& Ramli, K. (2017). Review of photoplethysmography based non-invasive continuous blood pressure methods. QiR 2017-2017 15th International Conference on Quality in Research (QiR): International Symposium on Electrical and Computer Engineering, 2017-Decem, 173178.

https://doi.org/10.1109/QIR.2017.8168477 